Through My Own Eyes 



\title{
Through My Own Eyes
}

SINGLE MOTHERS AND

THE CULTURES OF POVERTY

\author{
\&9 \\ Susan D. Holloway \\ Bruce Fuller \\ Marylee F. Rambaud \\ Costanza Eggers-Piérola
}

\author{
HARVARD UNIVERSITY PRESS \\ CAMBRIDGE, MASSACHUSETTS \\ LONDON, ENGLAND
}


Copyright () 1997 by the President and Fellows of Harvard College All rights reserved

Printed in the United States of America

Second printing, 2001

First Harvard University Press paperback edition, 2001

Library of Congress Cataloging-in-Publication Data

Through my own eyes : single mothers and the cultures of poverty /

Susan D. Holloway ... [et al.],

p. $\mathrm{cm}$.

Includes bibliographical references and index.

ISBN 0-674-89122-8 (cloth)

ISBN 0-674-00180-X (pbk.)

1. Welfare recipients-Massachusetts-Boston. 2. Single mothersMassachusetts-Boston. 3. Poor women-Massachusetts-Boston.

4. Poverty-United States-Case Studies. 5. Family policy-

United States. I. Holloway, Susan D.

HV99.B6T48 1997

$362.82^{\prime} 94^{\prime} 0974461-\mathrm{dc} 21 \quad 97-25240$ 
To the mothers, children, and teachers

who graciously welcomed us into their lives

89 
